\title{
Stable isotope modeling of the groundwater discharge in complex watersheds of the State of São Paulo, Brazil
}

\author{
Lucas Santarosa $^{1}$, Didier Gastmans ${ }^{2}$, and Carolina Quaggio ${ }^{3}$ \\ ${ }^{1}$ São Paulo State University \\ ${ }^{2}$ São Paulo State University \\ ${ }^{3}$ São Paulo State University (UNESP)
}

September 25, 2021

\begin{abstract}
The increasing pressure on water resources demands integrated multidisciplinary approaches to deal with environmental, scientific, and social issues related to water availability in watersheds. In large watersheds, many factors control hydrological processes, requiring the application of a methodology capable of describing water dynamics in complex situations. This study uses stable isotope $(2 \mathrm{H}$ and $18 \mathrm{O})$ modeling to characterize groundwater contribution in an area of heterogeneous hydrogeological framework and advanced anthropization, located in the Piracicaba-Capivari-Jundiaí (PCJ) and Tietê-Jacaré (TJ) water management units - central-eastern portion of the State of São Paulo, Brazil. Groundwater dynamics is controlled by the direct interaction of the rainfall regime with hydrogeological domains. The modeling performed in this study indicates that a portion ranging from 60 to $80 \%$ of the total volume of streamflow comes from groundwater discharge (for studied year). However, in the crystalline domain, the aquifer capacity of storing surplus water is smaller, increasing the importance of rainfall for the generation of direct runoff and maintenance of the streamflow. In most of the PCJ unit, there is a greater dependence on surface water and vulnerability to prolonged droughts. On the other hand, in the sedimentary areas, the contribution of groundwater discharge is around $80 \%$, showing that the aquifer storage capacity guarantees homogenization of the discharge throughout the year, and ensures water security in drought periods. This study attests to the successful application of stable isotope modeling to large basins, as the method is able to describe natural hydrological processes occurring in watersheds with a heterogeneous hydrogeological framework and the effects of the anthropogenic action. It is concluded that the use of stable isotopes can aid water resources management in expanding the capacity of monitoring surface and groundwater resources to identify negative effects on water availability.
\end{abstract}

\section{Hosted file}

MS_IsotopesPCJTJ_HP_20082021.doc available at https://authorea.com/users/436060/articles/ 538655-stable-isotope-modeling-of-the-groundwater-discharge-in-complex-watersheds-ofthe-state-of-s\%C3\%A3o-paulo-brazil 

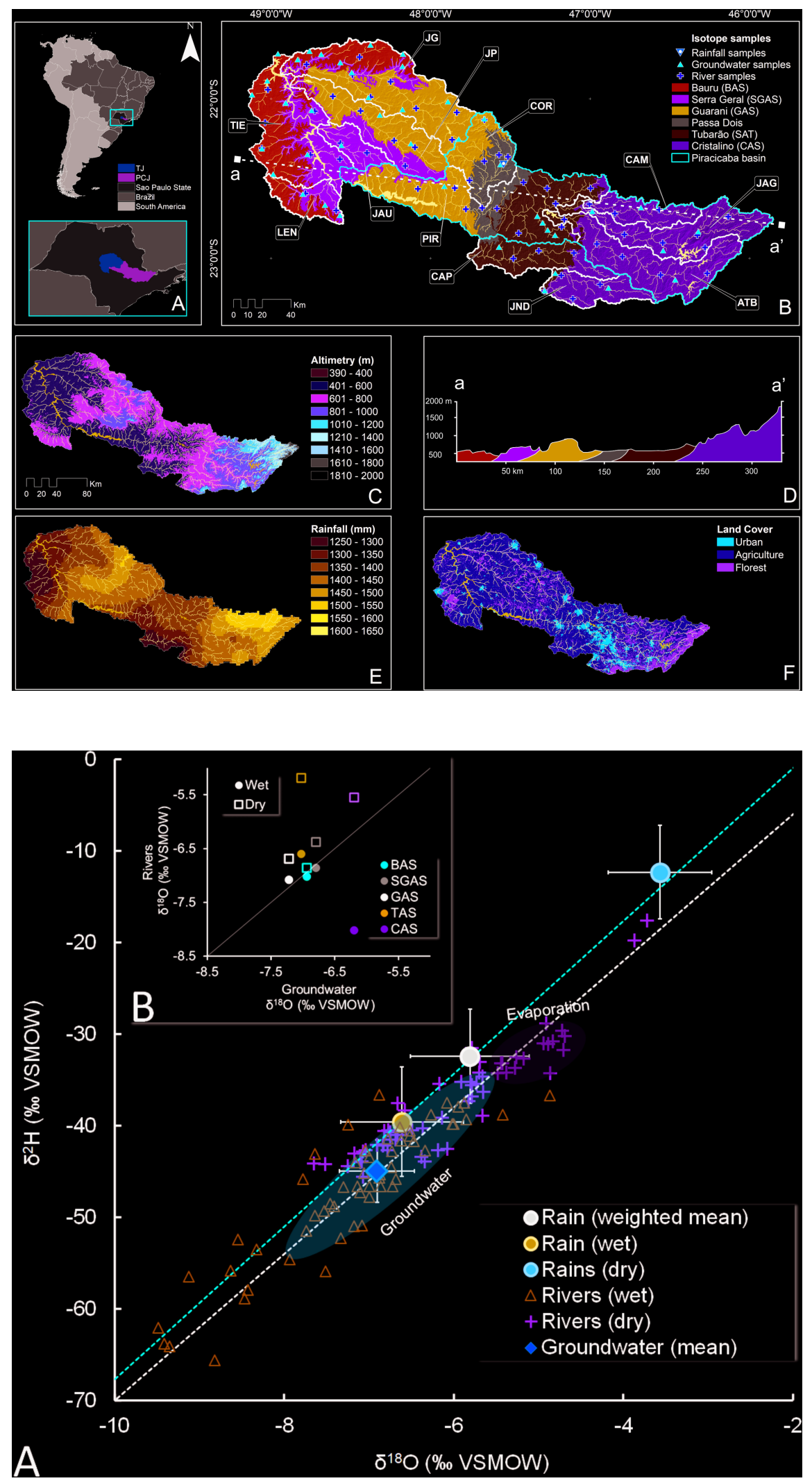

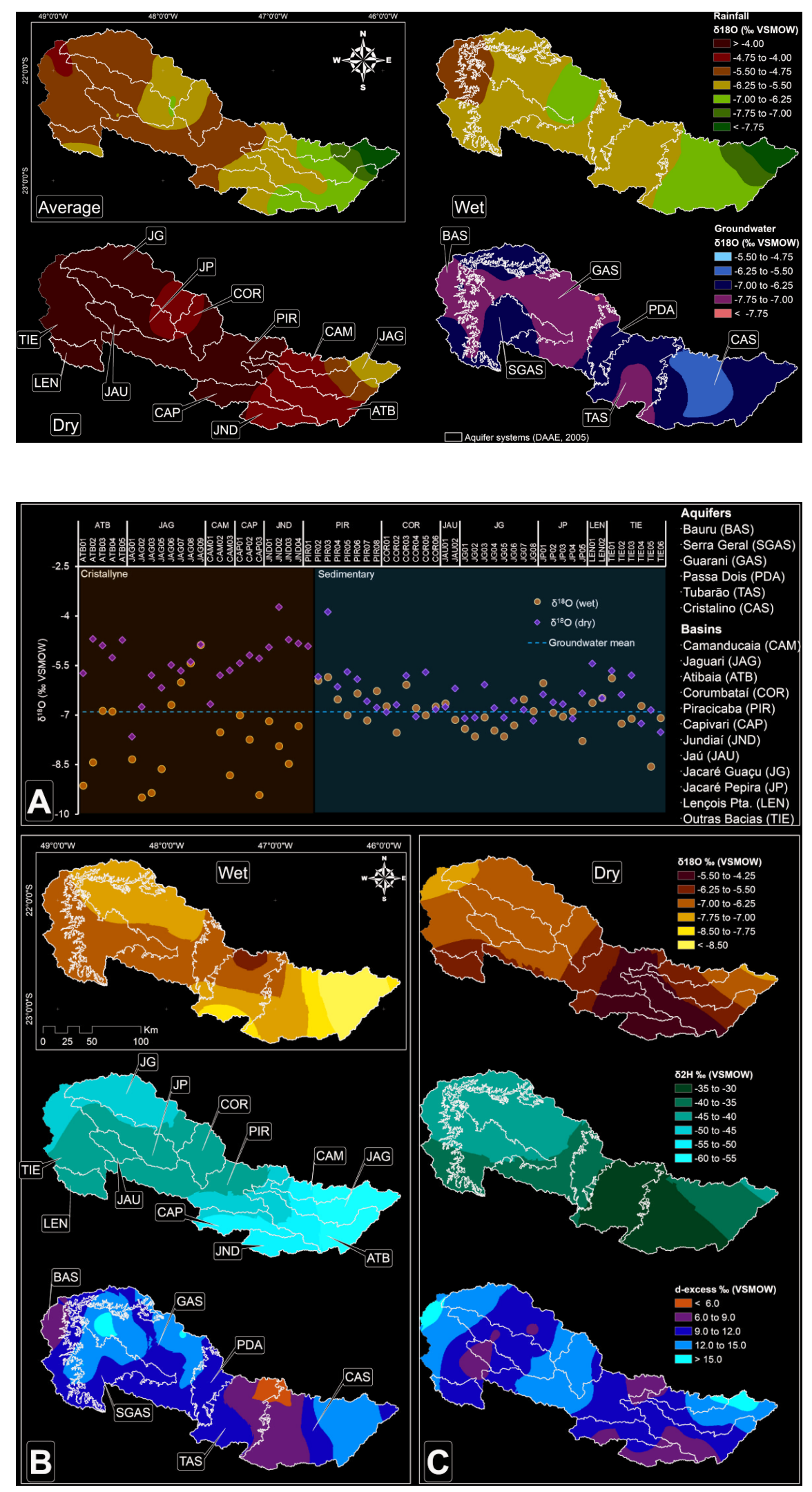

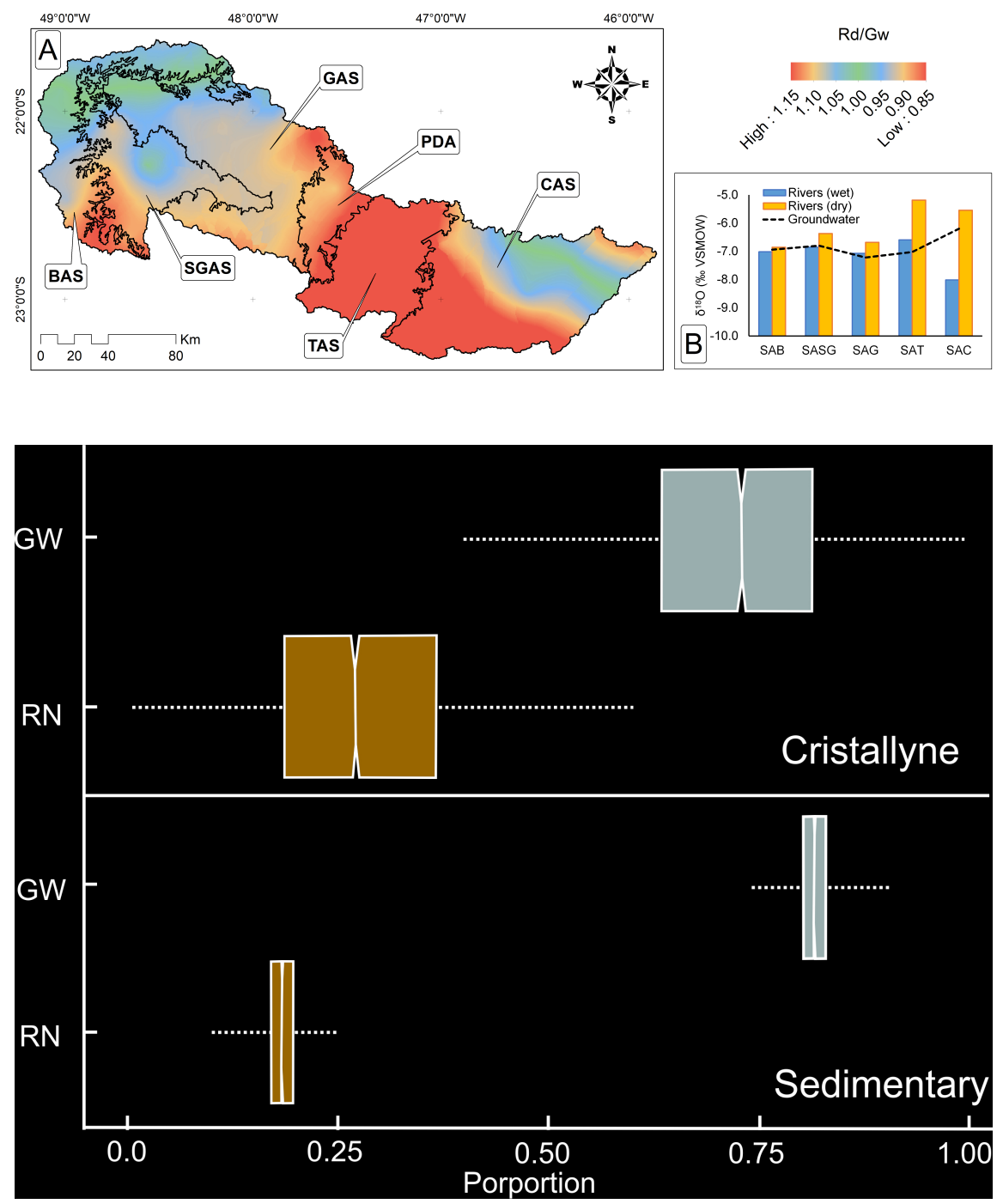

\section{Hosted file}

Tables.docx available at https://authorea.com/users/436060/articles/538655-stable-isotopemodeling-of-the-groundwater-discharge-in-complex-watersheds-of-the-state-of-s\%C3\%A3opaulo-brazil 

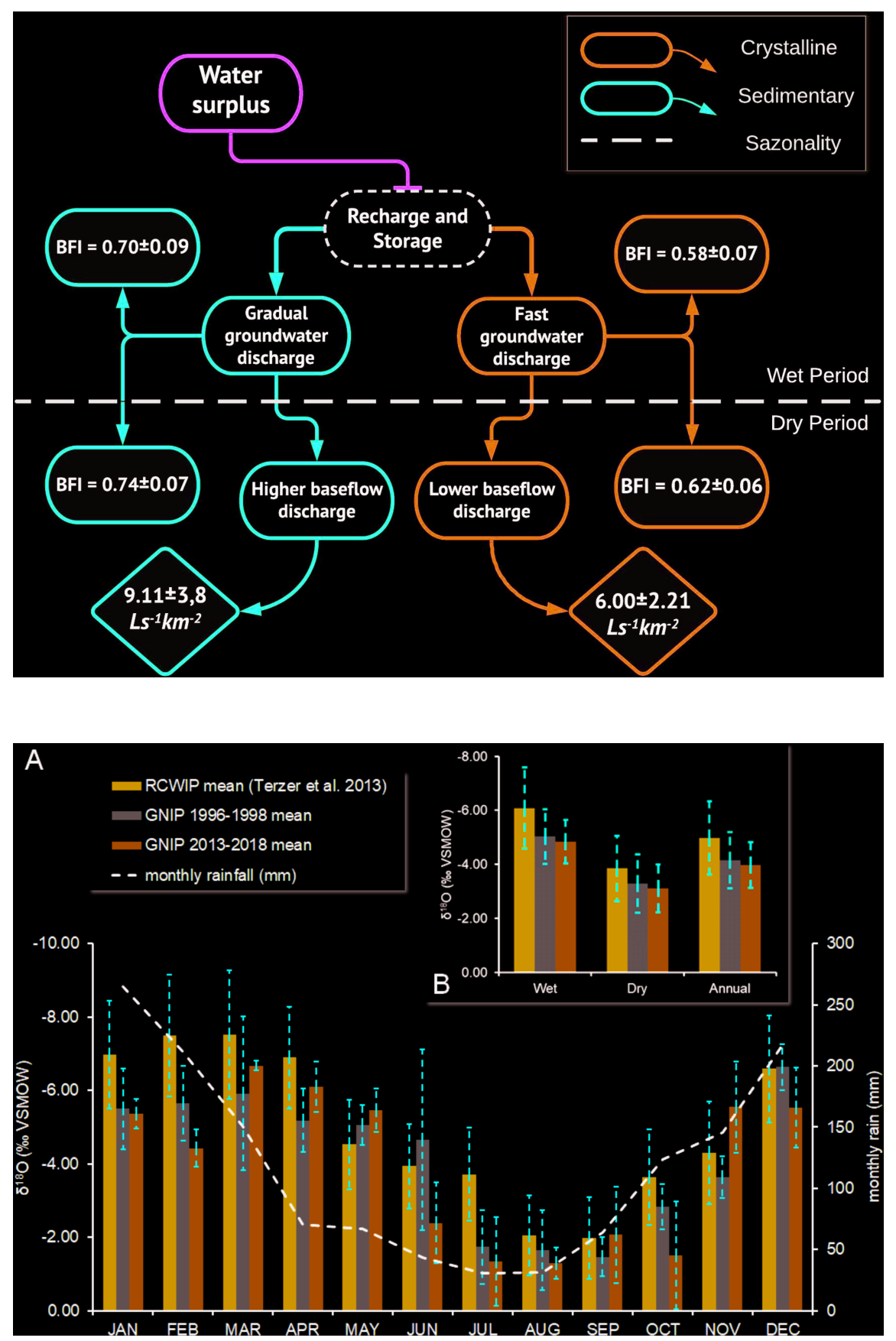


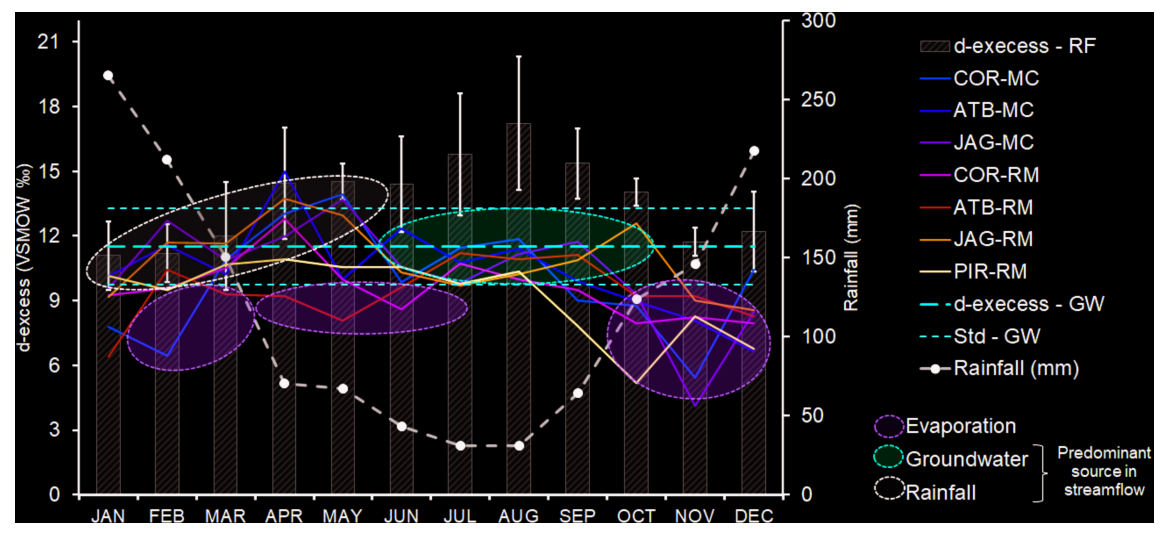

